\title{
Metodologia de criação de uma ferramenta didático- pedagógica de intervenção em doença renal crônica, segundo preceitos do letramento em saúde
}

\author{
Luanda Thais Mendonça Santos * \\ Lívia Botelho da Silva Sarkis * \\ Fernando Antonio Basile Colugnati * \\ Marcus Gomes Bastos *
}

\begin{abstract}
ResUmo
Considerando que o diagnóstico precoce da doença renal crônica (DRC) e o sucesso terapêutico da doença primária são fundamentais para a diminuição ou reversão da progressão da DRC, são necessárias intervenções que irão impactar positivamente conforme a precocidade de sua aplicação. O objetivo do presente trabalho foi desenvolver uma ferramenta didático pedagógica de intervenção em DRC. A criação da Ferramenta obedeceu a cinco etapas iniciais: sistematização do conteúdo; criação das imagens por um designer especializado; diagramação e edição do conteúdo; submissão a um Comitê de Especialistas e criação de um Manual do Mediador. A Ferramenta Didática de Intervenção em DRC foi concluída, dando origem a um instrumento capaz de abordar 11 itens de extrema importância para o tratamento da DRC: (1) Você sabe o que é Doença Renal Crônica?; (2) Acolhimento; (3) Sentimentos mediante o diagnóstico; (4) Definição de DRC; (5) Caminho do sangue; (6) Mitos e verdades; (7) Sinais e sintomas; (8) Fatores de risco; (9) Alimentação; (10) Atividade física; e (11) Tratamento. A Ferramenta Didático-Pedagógica de Intervenção em DRC é um instrumento facilitador da aprendizagem, por ter uma estrutura lúdica, dialógica e dinâmica, cujo intuito é impactar nos desfechos de forma positiva.
\end{abstract}

Palauras-chave: Estratégias. Educação em Saúde. Alfabetização em Saúde. Insuficiência Renal Crônica.

\section{INTRODUÇÃO}

A Doença Renal Crônica (DRC) é considerada, atualmente, além de um grave problema de saúde pública, a grande epidemia deste milênio. No Brasil, as atenções com a DRC convergem, quase que exclusivamente, para seu estágio mais avançado, situação que demanda Terapia Renal Substitutiva (BASTOS et al., 2011).

Conquanto o encaminhamento para o médico nefrologista seja uma realidade cada vez mais documentada, a maioria dos indivíduos com DRC desconhecem a existência da doença, acarretando, portanto, atraso no início da terapia de diálise (WRIGHT et al., 2011).

O controle rigoroso da pressão arterial, a diminuição da proteinúria, o controle glicêmico, a cessação do fumo, o combate à obesidade, a restrição da ingesta proteica, o controle da hiperlipidemia são fundamentais para diminuir a progressão da DRC (BASTOS et al., 2004).

Segundo o diagnóstico da doença renal primária, as causas mais frequentes são hipertensão arterial $(35 \%)$ e diabetes $(28 \%)$. Em virtude de dados tão alarmantes, faz-se emergencial atuar para prevenir, pois, na maioria dos casos, a deterioração dos órgãos, e principalmente da função renal, é assintomática, evidenciando a necessidade de detecção precoce e intervenções imediatas, cujo intuito será retardar a progressão de uma lesão (SESSO et al., 2010).

Portanto, o melhor caminho a ser trilhado ainda é o da prevenção, melhorando a qualidade de vida dos usuários, através da adoção de estilos de vida mais saudáveis, minimizando danos, incapacidades, riscos e gastos (LIMA, 2009).

A prevenção, a promoção e a educação em saúde, implementadas de forma adequada, contribuem sobremaneira para a redução de gastos pelo Sistema Único de Saúde (SUS), haja vista que internações por complicações da hipertensão, diálise e transplante renal, tratamento medicamentoso para diabéticos, no Brasil, apresentam custos em torno de 1,4 bilhões de reais por ano (PACHECO et al., 2006).

É atribuída à educação em saúde a capacidade de controlar as complicações advindas das doenças e proporcionar estilos de vida mais saudáveis aos usuários. A educação em saúde seria um instrumento

* Universidade Federal de Juiz de Fora, Faculdade de Medicina, Departamento de Clínica Médica - Juiz de Fora, MG. E-mail: luandaprof@gmail.com

HU Revista, Juiz de Fora, v. 43, n. 3, p. 255-263, jul./set. 2017 
de emancipação do homem, devendo ser desenvolvida dentro de uma concepção dialógica (TORRES, 2009).

Freire (2006) postula uma educação problematizadora, dialógica. Uma educação autêntica e significativa nos faz pensar em uma abordagem que tenha origem nos anseios, dúvidas, esperanças, visões de mundo do educador e do educando. Assim, a educação seria a relação e a interação entre sujeitos, mediada pela realidade; seria uma busca pela reconstrução do conhecimento verdadeiramente significativo para a vida dos sujeitos, através da autonomia (FREIRE, 2006).

Educação em Saúde está intrinsecamente ligada ao Letramento em Saúde (LS) que, por sua vez, referese ao conhecimento, motivação e competência dos pacientes para acessar, compreender, avaliar e aplicar informação em saúde, de forma a fazer julgamentos e tomar decisões cotidianas, no que tange ao autocuidado, prevenção de doenças e promoção da saúde, buscando manter ou melhorar a qualidade de vida (SORENSEN et al., 2002).

Quando se fala em LS, deve-se pensar em dois extremos que convergem: o primeiro decorrente da má-comunicação médico paciente, possivelmente ocasionada pelo desconhecimento dos profissionais de saúde das ferramentas indispensáveis no trato de usuários com risco potencial de apresentarem baixo LS; o segundo provém de inabilidades dos usuários, de ordem cognitiva e/ou funcional para entender informações imprescindíveis para o autocuidado.

A comunicação entre médicos e usuários consiste em um relevante debate em pesquisas na área da saúde, pois garante benefícios ao paciente, propiciando adesão e sucesso no tratamento, acarretando melhora na qualidade de vida, redução de gastos com a saúde, redução da ansiedade do paciente durante a consulta médica, aumento da confiança no profissional de saúde (MULLER, 2010).

Assim sendo, com base em todas essas informações, foi desenvolvida uma Ferramenta Didático Pedagógica de Intervenção em DRC, baseada nos preceitos da Educação em Saúde e do Letramento em Saúde, composta, basicamente, por ilustrações, cujo intuito é fazer associações metafóricas, visando ao aprendizado pleno das informações fornecidas.

\section{Material e Métodos}

O equipamento inovador de exame do campo visu $\mathrm{O}$ processo de construção da Ferramenta foi composto por cinco fases. Na primeira fase, chamada de sistematização do conteúdo, foi feito um levantamento, por meio de pesquisas na literatura, com o intuito de avaliar o nível de conhecimento dos pacientes encaminhados pelas Unidades Básicas de Saúde sobre o tema DRC. Sabendo das lacunas de conhecimento dos pacientes, foi composto um comitê de especialistas formado por um médico nefrologista, uma psicóloga, um educador físico, uma nutricionista, uma enfermeira, um farmacêutico, uma assistente social, uma pedagoga, uma linguista, sendo todos profissionais experientes na área de nefrologia. Depois de dois encontros, foi decidido que seriam abordados assuntos como definição da doença, diagnóstico, aceitação da doença, sinais e sintomas, grupos de risco, indicações nutricionais, atividade física, tratamentos.

$\mathrm{Na}$ segunda fase, foi realizada uma pesquisa minuciosa para criar imagens que representassem, de forma fidedigna, as informações pretendidas. $\mathrm{O}$ processo de criação foi realizado por um designer especializado.

A terceira fase foi de edição e diagramação das imagens, conforme os quesitos da primeira fase.

$\mathrm{Na}$ quarta fase, as imagens foram submetidas a um Comitê de Especialistas composto por uma equipe multidisciplinar, a fim de avaliar a relevância, a coerência e a apresentação das informações, a adequação da composição visual, a atratividade e a organização. Foram feitas as modificações sugeridas pelos especialistas.

$\mathrm{Na}$ quinta fase, foi criado um manual do mediador que é um informativo descritivo de toda Ferramenta de intervenção didático pedagógica em DRC que deve ser estudado por todos os sujeitos envolvidos na aplicação e ou na utilização do material. A ferramenta de intervenção didático pedagógica ficou disponível para utilização de qualquer membro da equipe multidisciplinar, desde que, devidamente capacitado (BAKHTIN, 2003).

Porseruminstrumento facilitadorde aprendizagem, é imprescindível o uso de: (1) linguagem adequada, sem tecnicismos; (2) exploração das imagens; (3) treinamento da escuta; (4) observação da linguagem não-verbal; (5) exposição e exploração, somente do conteúdo necessário (KOCH, 2003).

O material foi desenvolvido em flip chart, mas as imagens também podem ser projetadas em data show, conforme os recursos disponíveis.

Recomenda-se que não sejam trabalhados todos os assuntos no mesmo dia. Primeiro, deve-se avaliar, por meio de questionário de sondagem, o nível de conhecimento dos usuários sobre a doença e por meio de um instrumento fidedigno, o nível de LS dos mesmos. De posse dessas informações, será possível dividir os assuntos e determinar o quanto os temas deverão ser aprofundados.

O papel do educador em saúde, junto a essa intervenção, será, após a capacitação dos profissionais 
envolvidos na aprendizagem das técnicas de comunicação, observar a condução dos encontros, a atuação do mediador, bem como a participação dos usuários, a fim de evitar problemas decorrentes da má-comunicação.

\section{Resultados}

Objetivando uma melhor compreensão das estratégias que subjazem à criação da Ferramenta Didática de Intervenção em DRC, será feita uma discussão sobre cada item abordado.

O item 1 (Figura 1), "Você sabe o que é Doença Renal Crônica?", objetiva explorar a imagem dos rins e sua localização no corpo humano. Deve-se atentar para o fato de que esse é o primeiro contato com o usuário na intervenção, portanto não é aconselhável aprofundar em informações sobre a doença.

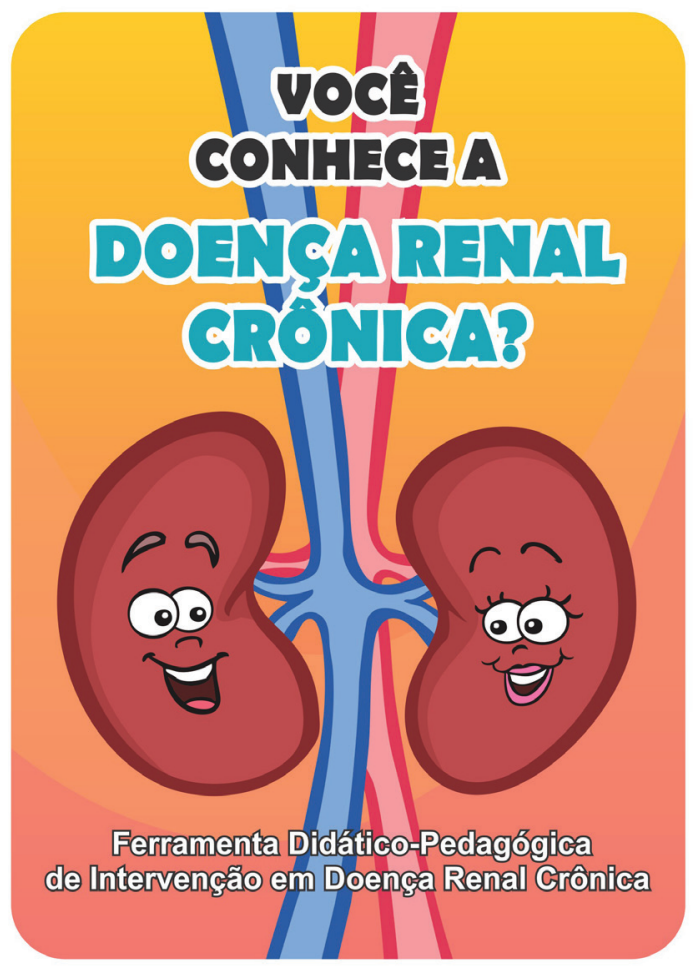

Figura 1: Você sabe o que é Doença Renal Crônica? Fonte: Os autores (2018).

No item 2 (Figura 2), "Acolhimento", a imagem representa a metáfora central, da qual serão retiradas todas as outras metáforas decorrentes. O mediador deverá explorar a familiaridade do paciente com o contexto: praça, farmácia, Unidade de Atenção Primária à Saúde (UAPS), mercado, casas, botequim, feirinha. É uma importante oportunidade para realizar uma sondagem sobre hábitos de vida (hábitos alimentares, atividade física); fornecer informações sobre a farmácia popular (direitos dos usuários), trabalhando, assim, o letramento político, uma vez que semelhantemente ao observado em outras doenças crônicas, é possível que as condições socioeconômicas dos usuários com DRC tenham um impacto desfavorável na evolução da doença. Assim, cabe ao mediador, preferencialmente a um assistente social, esclarecer os usuários quanto aos seus direitos constitucionais, motivar o indivíduo a manter as suas atividades laborativas e orientar sobre os diferentes programas de acesso gratuito a medicamentos (programa de cesta básica de medicamentos), os benefícios e os serviços disponíveis para complementar os cuidados de saúde dispensados aos usuários com DRC.

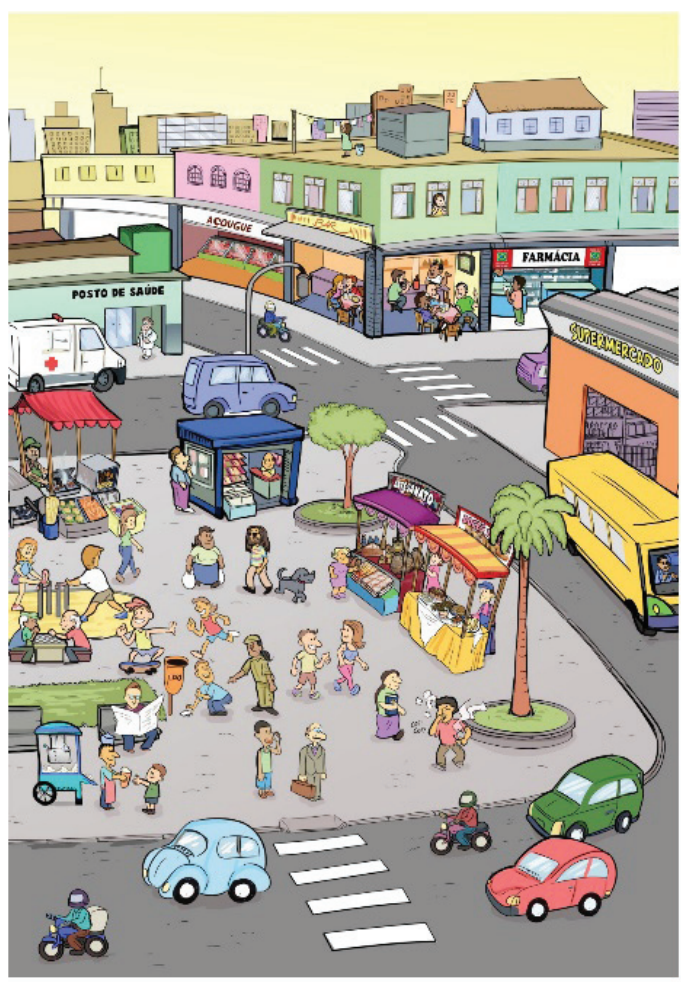

Figura 2: Acolhimento Fonte: Os autores (2018).

O item 3 (Figura 3), de extrema importância, remete aos "Sentimentos Mediante o Diagnóstico" e deverá, se possível, ser abordado pela equipe de psicologia, visando explorar as imagens representativas dos sentimentos de raiva, medo, negação, tristeza e aceitação, reações as quais grande parte dos pacientes vivenciam, quando recebem o diagnóstico de uma doença crônica.

Deve-se permitir ao usuário expressar suas emoções. Para aumentar a probabilidade de que o paciente seja aderente ao tratamento, reforce sempre as emoções positivas. Essa postura apresenta-se útil para eliminar um comportamento não adaptativo.

HU Revista, Juiz de Fora, v. 43, n. 3, p. 255-263, jul./set. 2017 


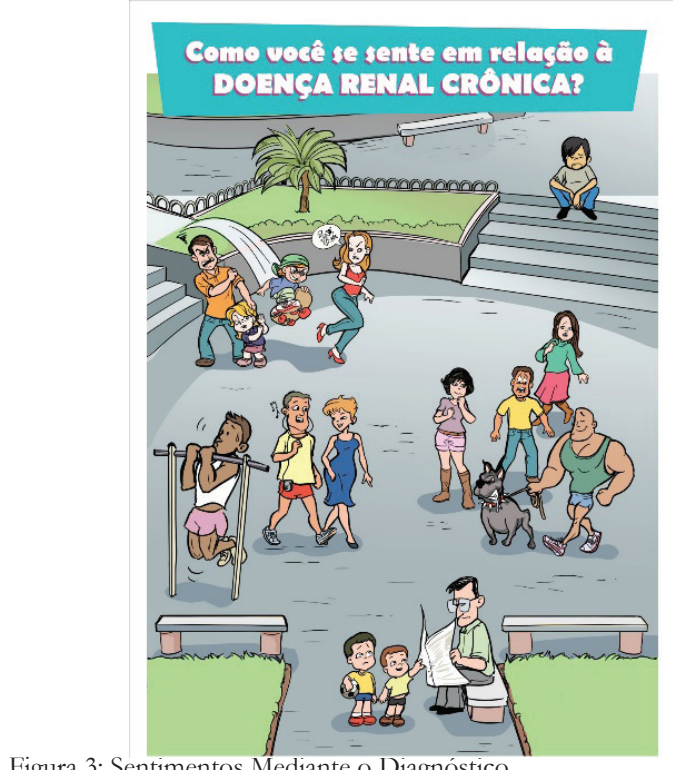

Figura 3: Sentimentos Mediante o Diagnóstico

Fonte: Os autores (2018).

O item 4 (Figura 4), "Definição de DRC", deve ser conduzido tentando extrair dos usuários o que eles sabem sobre a DRC. Deve-se explorar o desenho do filtro de água e a associação pretendida com o funcionamento dos rins. O mediador precisará explicar a função dos rins, através de uma linguagem condizente com o grupo de pacientes em intervenção. Além disso, deve ser esclarecido como é feito o diagnóstico da DRC, ressaltando a necessidade de exames de sangue e urina.

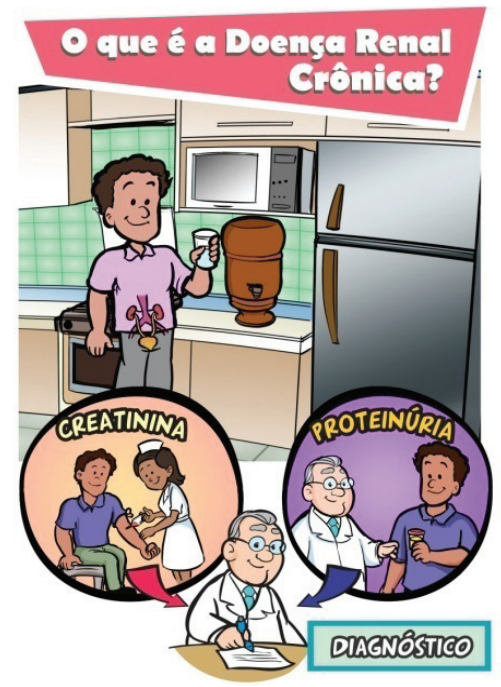

Figura 4: Definição de DRC

Fonte: Os autores (2018).

O item 5 (Figura 5), "O Caminho do Sangue", tem como principal objetivo despertar a atenção dos usuários para a importância dos rins em relação ao restante do corpo. Caso o usuário peça alguma explicação mais detalhada, mencionar que os rins removem os produtos residuais do metabolismo das proteínas, contribuindo para a manutenção das quantidades exatas de água e eletrólitos (sódio e potássio). Os produtos residuais excedentes são removidos pela urina. Quando os rins adoecem, as funções renais deixam de ser executadas adequadamente, os produtos residuais, os eletrólitos (sódio e potássio) e a água excedentes acumulam-se no organismo. É importante lembrar que informações adicionais só poderão ser fornecidas mediante pedido do usuário e percepção de sua capacidade de aprofundamento. Caso contrário, o excesso de informação poderá prejudicar o entendimento.

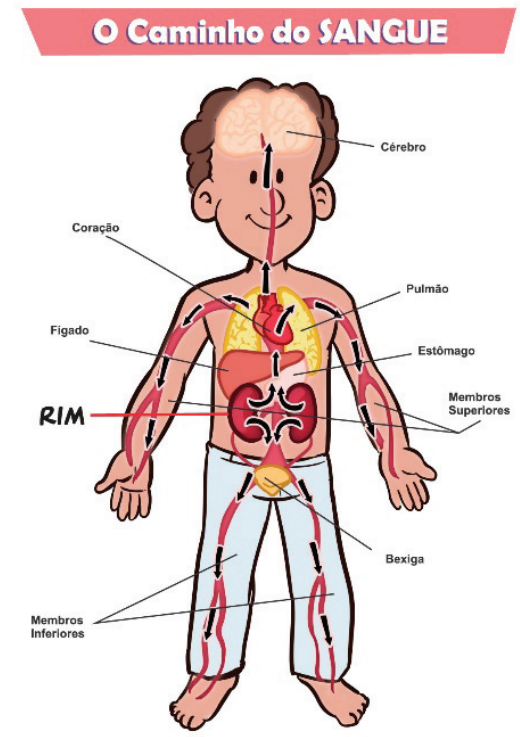

Figura 5: O Caminho do Sangue Fonte: Os autores (2018).

No item 6, "Mitos e Verdades", serão utilizados cartões contendo informações verdadeiras e falsas sobre DRC e os usuários deverão levantar placas verdes ou vermelhas, conforme concordem ou discordem dos conteúdos apresentados. Essa atividade lúdica promove a troca de saberes e o esclarecimento de possíveis dúvidas.

O item 7 (Figura 6), "Sinais e Sintomas", permite a exploração das imagens e a sondagem sobre a familiaridade dos usuários com o assunto. É imprescindível discutir o porquê de cada sinal ou sintoma, atentando para a complexificação das informações de acordo com o nível de LS dos usuários. Deve-se tomar o cuidado de esclarecer que a presença de um ou dois sintomas ou sinais não significa que a pessoa esteja com problemas renais. Os sinais e sintomas seriam sinalizadores para uma investigação mais cuidadosa do médico. 


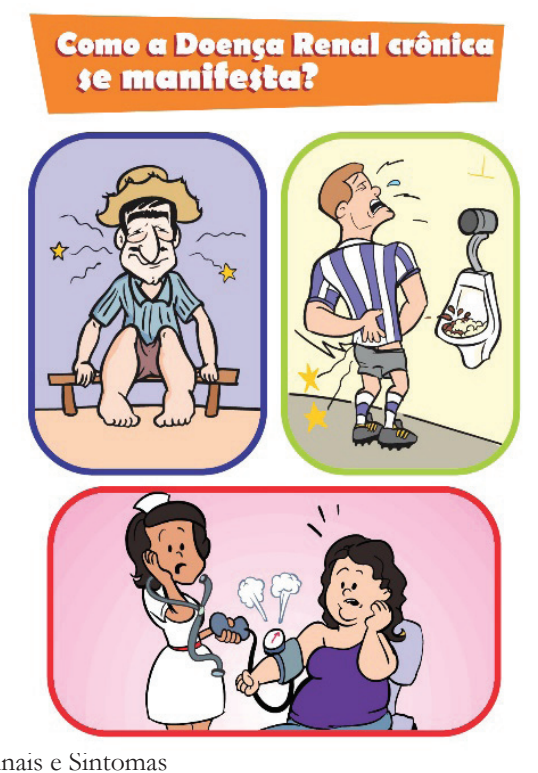

Figura 6: Sinais e Sintomas

Fonte: Os autores (2018).

No item 8 (Figura 7), "Fatores de Risco", serão contadas as histórias dos personagens, com o intuito de familiarização dos usuários com os estudos de caso. Deixar que os próprios usuários descubram quais foram os fatores que desencadearam a DRC nos personagens. Discutir metas de pressão arterial (pressão alta), glicemia (açúcar no sangue), atividade física, redução do fumo, dieta adequada, à medida que os personagens contarem suas histórias. A identificação de padrões de comportamento e atitudes nos fatores que desencadearam a DRC nos personagens, permite aos psicólogos reconhecer o impacto dos pensamentos, atitudes e emoções sobre a doença e estabelecer correlações entre cognição, afeto e comportamento.

O item 9 (Figura 8), "Alimentação", deverá, preferencialmente, ser conduzido por um nutricionista. Caso o mediador não tenha conhecimento especializado sobre o assunto, instruções básicas estão contidas no Manual do Mediador.

Os objetivos da terapia nutricional são, basicamente, contribuir para retardar a progressão e as complicações da DRC, reduzir os sintomas urêmicos decorrentes do acúmulo de produtos nitrogenados e eletrólitos, prevenir e corrigir alterações hormonais e metabólicas e prevenir ou tratar alterações nutricionais, como a desnutrição energético-proteica e a obesidade. Em um segundo momento, poderá ser feita uma atividade lúdica, na qual os pacientes deverão separar os alimentos em grupos, conforme orientações sobre o que deve ser ingerido de forma moderada, o que é proibido e o que é permitido.

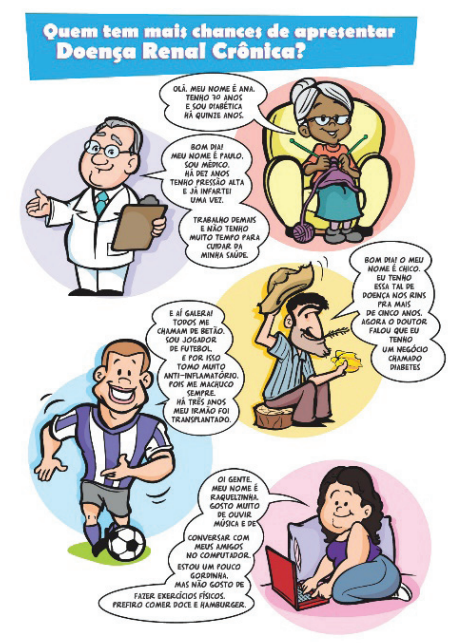

Figura 7: Fatores de Risco

Fonte: Os autores (2018).

Outra atividade igualmente lúdica é fornecer um cartão ao paciente, no qual ele deverá traçar, conforme seu cotidiano, seu próprio cardápio. Essa atividade deverá ser acompanhada pelo nutricionista, mantendo um ambiente de discussão, evitando imposições que possam desencadear negações em relação ao autocuidado. Atentar para hábitos de vida e condição financeira do usuário. Reforçar as explicações sobre restrições e possíveis substituições (Figura 3).

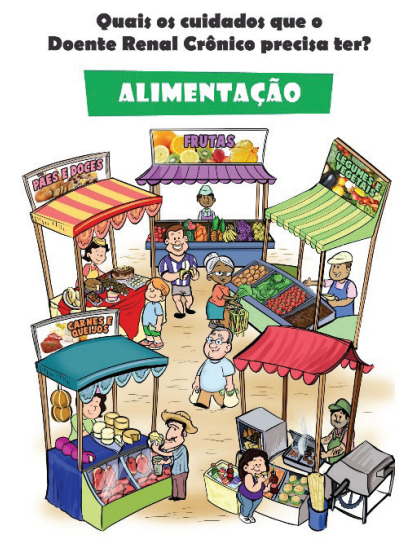

Figura 8: Alimentação

Fonte: Os autores (2018).

O item 10 (Figura 9), "Atividades Físicas", deverá ser orientado, preferencialmente, por um educador físico que discutirá com os usuários as imagens representativas de atividades físicas diárias. Discutir os benefícios da atividade física e do exercício físico sobre o controle da pressão arterial, controle glicêmico, diminuição do colesterol, controle de peso associado à dieta. $\mathrm{O}$ mediador deverá traçar, com o usuário, um plano de atividade física e/ou exercícios físicos

HU Revista, Juiz de Fora, v. 43, n. 3, p. 255-263, jul./set. 2017 
semanais, conforme o cotidiano e a profissão de cada indivíduo. Orientações claras sobre a condução deste item estão descritas no Manual do Mediador.

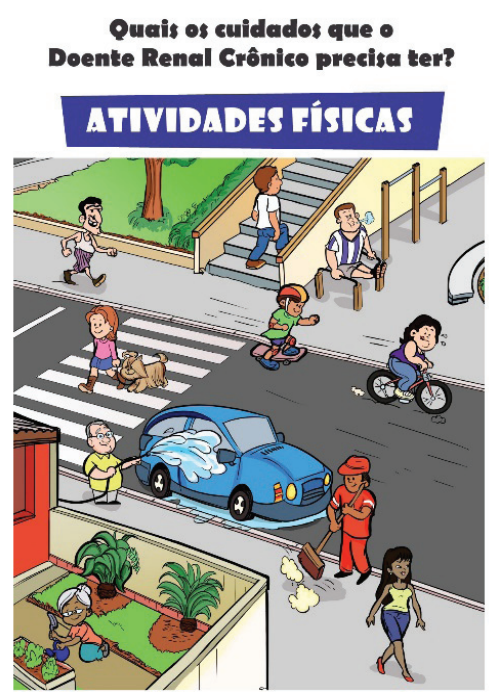

Figura 9: Atividades Físicas

Fonte: Os autores (2018).

O item 11 (Figura 10), “Tratamento", deverá ser supervisionado, se possível, por uma psicóloga, pois discussões sobre prognósticos podem causar desequilíbrios emocionais nos usuários. Apresentar as principais formas de tratamento, com as devidas explicações sobre benefícios de cada método e, posteriormente, deixar que o paciente discuta uma terapia que se adapte melhor ao seu estilo de vida. Faz-se necessário discutir o que é e como deve ser conduzido o tratamento conservador, a terapia renal substitutiva (hemodiálise e diálise peritoneal) e, finalmente, o transplante.

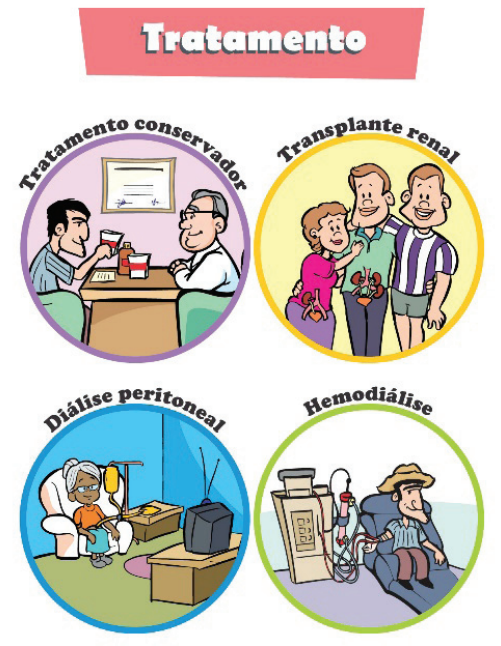

Figura 10. Tratamento

Fonte: Os autores (2018).

\section{Discussão}

Para que se compreenda a metodologia utilizada na criação dessa Ferramenta, faz-se primordial o entendimento de alguns pressupostos.

O modo como uma pessoa se sente está associado ao modo como as situações são pensadas e interpretadas. A situação em si "doença" não determina diretamente como uma pessoa se sente ou se comporta; sua resposta emocional é determinada por sua percepção da situação. Por isso, é de extrema importância a abordagem do item 2, Acolhimento, pois nesse momento o usuário expressará, de forma espontânea, seu esquema de crenças, hábitos, sua percepção da realidade.

É imprescindível que o mediador, bem como os demais profissionais envolvidos na intervenção, não faça juízos de valor, conotando concordância ou discordância com a expressão do grupo. Apenas reforços positivos devem ser utilizados. O mesmo acontece no item 3, Sentimentos Mediante o Diagnóstico, pois nesse momento, os usuários se identificarão com os contextos e sentimentos de medo, raiva, negação, tristeza poderão aflorar e, caso mal conduzidos pelo mediador, o paciente poderá não ser aderente à intervenção (MARCUSCHI, 2008).

O item 4, A Definição da DRC, gera dúvidas quando se apresentam as palavras creatinina e proteinúria. Acredita-se que devem ser utilizados os nomes adequados, desde que sejam devidamente esclarecidos. Usar termos como "hipertensão arterial" é imprescindível para a implementação do nível de LS do paciente, desde que o termo "pressão alta" seja a ele associado. Privar o usuário de conhecer os nomes adequados impede o empoderamento necessário para que este possa navegar sozinho no sistema de saúde, adquirindo independência, pois não se pode garantir que todos os profissionais de saúde tenham uma boa comunicação com seus pacientes.

O item 5, Caminhos, mostra o processo de circulação do sangue no corpo humano.

No item 6, Mitos e Verdades, os usuários são alertados quanto a crendices que podem maquiar a aquisição das informações corretas. Por ser um momento de interação, no qual os pacientes se sentem muito à vontade, atentar para não expressar críticas ou avaliações negativas referentes ao conhecimento prévio do grupo.

O item 7, Sinais e Sintomas, deve ser conduzido de modo que o paciente esteja consciente de que a apresentação dos sintomas descritos não garante $\mathrm{o}$ diagnóstico da DRC, que só poderá ser feito pelo médico, mediante exames comprobatórios.

Considerando-se que o sucesso do tratamento é obtido através da adesão e que a adesão é fortemente 
influenciada pela qualidade da comunicação entre profissionais de saúde e paciente, entende-se que uma boainformaçãoé uma ferramenta eficaz para promover a adesão de usuários e familiares ao tratamento médico (OLIVEIRA; GOMES, 2004). Portanto, fazse necessário o uso de uma linguagem clara, livre de tecnicismos. $\mathrm{O}$ uso de analogias e exemplos permite o entendimento de situações desconhecidas, contudo deve-se tomar extremo cuidado para não infantilizar a intervenção, subestimando a maturidade dos usuários.

Outro problema remete à identificação de usuários com LS inadequado. Estudos atestam que, no âmbito da saúde, indivíduos apresentam considerável dificuldade na leitura dos textos típicos deste contexto situacional. Essa limitação, associada ao fato de os profissionais de saúde desconhecerem o grau de letramento de seus usuários, o que os faz utilizar uma linguagem extremamente especializada, favorece a ocorrência de desfechos clínicos negativos (NATIONAL WORK GROUP ON LITERACY AND HEALTH, 1998). Neste sentido, nos Estados Unidos (EUA), o Grupo de Trabalho Nacional sobre Letramento e Saúde (PAASCHE-ORLOW et al., 2005) alertou sobre a inabilidade dos profissionais de saúde em reconhecer usuários com LS inadequado, devido ao desconhecimento do tema, e uma pesquisa mostrou que os médicos têm dificuldade em detectar níveis inadequados de LS em seus usuários NATIONAL WORK GROUP ON LITERACY AND HEALTH, 1998).

Portanto, muitos advogam que o LS deva ser adequadamente avaliado para identificar os usuários com maior risco para desfechos clínicos inadequados (PAASCHE-ORLOW et al., 2005). Considerando que o manejo bem sucedido de muitas doenças agudas e crônicas é influenciado pelo entendimento das informações de saúde, oferecer suporte adicional aos indivíduos que possam apresentar dificuldade em entender estas informações, possivelmente, influenciará nos desfechos clínicos.

Sendo assim, a utilização de um instrumento adequado para avaliar o LS, desenvolvido consoante a realidade brasileira, é de extremo valor para identificação do nível de LS e orientação adequada das intervenções.

É importante destacar que o LS é um fenômeno contextualizado. Tanto é assim que o relatório sobre LS do Instituto de Medicina Americano não enquadra o LS inadequado como um problema do paciente, mas sim um desafio da assistência à saúde e dos profissionais de saúde pública (KIRSCH et al., 2005).

Assim sendo, no item 8, Fatores de Risco, são apresentadas as histórias dos personagens que dialogam com os usuários através da intervenção.
Cada personagem assume um estereótipo de uma história clínica, com a qual os pacientes facilmente se identificam, tornando o conteúdo mais leve e mais divertido.

Especificamente, o conceito de LS deveria incorporar, além das habilidades utilizadas pelo indivíduo quando da tomada de decisões, demandas contextuais enfrentadas por eles frente (1) a condição clínica específica; (2) as habilidades de comunicação do profissional de assistência à saúde; (3) as demandas complexas e concorrentes de vários textos sobre saúde e de saúde pública 8 disponíveis; (4) a estrutura e função de serviços clínicos e de saúde pública que assumem o LS como universalmente adequado e demandam auto-representação e vigilância e (5) a ênfase que a sociedade coloca no indivíduo mais do que em determinantes ecológicos de saúde (PAASCHE-ORLOW, 2011).

Devido a essas informações, foram criados os itens 9, Alimentação e 10, Atividades Físicas, a fim de que os usuários recebam as informações pertinentes ao autocuidado, trabalhando sempre a adesão como ferramenta de prevenção de piores desfechos clínicos.

Deve-se frisar que LS não se refere apenas à comunicação através de materiais escritos, engloba também acesso ao sistema de saúde e aos serviços de prevenção, compreensão sobre o diagnóstico e tratamento a ser seguido, e o desenvolvimento da capacidade de tomar decisões a partir de informações sobre saúde para melhorar o seu estado geral de saúde (EVANS; STODDART, 2003).

Por isso, aconselha-se a abordagem do Letramento político, no decorrer de toda a Ferramenta, instruindo o usuário sobre seus direitos e a melhor forma de reivindicá-los.

Finalmente, o item 11, Tratamento, versa sobre Tratamento Conservador, Terapia Renal Substitutiva e Transplante, temas que, segundo nossa experiência com a aplicação da Ferramenta, não devem ser trabalhados por último, uma vez que causa desconforto e medo nos pacientes, ainda que seja abordado por meio de ilustrações, metáforas e analogias.

O maior problema enfrentado na aplicação da Ferramenta de Intervenção sobre DRC é a aderência às intervenções. Como o paciente é recrutado em sala de espera e precisa se comprometer a comparecer às sessões, ainda que não tenha consulta marcada, muitos não comparecem em todos os módulos. Infelizmente, isso faz parte da cultura brasileira, muito diferente da realidade europeia, por exemplo. Aconselha-se, portanto, a intervenção em consultas coletivas ou salas de espera, pois nesse momento são reunidos um maior número de pacientes..

HU Revista, Juiz de Fora, v. 43, n. 3, p. 255-263, jul./set. 2017 


\section{Conclusão}

Embasados nas informações supracitadas, entende-se que, para a diminuição ou reversão da progressão da DRC, são necessárias intervenções que irão impactar positivamente conforme a precocidade de sua aplicação; nesse contexto, o sucesso terapêutico da doença primária é de fundamental importância para a prevenção da falência funcional renal.

Acredita-se que a Ferramenta Didático-Pedagógica de Intervenção em DRC, caso aplicada segundo capacitação, através do Manual do Mediador, por compreendera aprendizagem de modo multidisciplinar abrangendo, assim, uma visão holística do indivíduo neste processo de aquisição de saberes, promoverá o real aprendizado.

Destaca-se o papel primordial do mediador que irá apenas interferir no momento de concluir a discussão e dirimir possíveis dúvidas que surjam no decorrer da intervenção.

\section{FINANCIAMENTO}

FAPEMIG (Fundação de Amparo à Pesquisa do Estado de Minas Gerais) pelo fornecimento de auxílio financeiro.

\title{
Methodology of creating a pedagogic-didactic tool for intervention in chronic kidney disease, precepts of health literacy
}

\begin{abstract}
Considering that the early diagnosis of chronic kidney disease (CKD) and the therapeutic success of the primary disease are fundamental for the reduction or reversal of the progression of CKD, early interventions are required in order to positively impact in course of the disease. The objective of this study was to develop a pedagogical didactic tool for intervention in CKD. The development of the Tool obeyed five initial stages: systematization of the content; creation of images by a specialized designer; layout and content editing; submission to a Committee of Experts, and creation of a Manual of the Mediator. The Didactic Intervention Tool in DRC was completed, originating an instrument capable of addressing 11 items of extreme importance for the management of CKD: (1) Do you know what is Chronic Renal Disease ?; (2) Reception; (3) Feelings through diagnosis; (4) Definition of DRC; (5) Blood flow through the kidneys; (6) Myths and truths; (7) Signs and symptoms; (8) Risk factors; (9) Eating; (10) Physical activity; and (11) Treatment. The DidacticPedagogical Intervention Tool in DRC is an instrument that facilitates learning, because it has a playful, dialogic and dynamic structure, that aims to positively impact in the outcomes of the disease.
\end{abstract}

Keywords: Strategies. Health Education. Health Literacy. Renal Insufficiency, Chronic.

\section{REFERÊNCIAS}

BAKHTIN, M. Os gêneros do discurso. São Paulo: Editora Martins Fontes, 2003.

BASTOS, M. G. et al. Doença renal crônica: problemas e soluções. Jornal Brasileiro de Nefrologia, v. 26, n. 4, p. 202-215, set. 2004.

BASTOS, M. G. ; KIRSZTAJN, G. M. Doença renal crônica: importância do diagnóstico precoce, encaminhamento imediato e abordagem interdisciplinar estruturada para melhora do desfecho em pacientes ainda não submetidos à diálise. Journal Brasileiro de Nefrologia, v. 33, n. 1, p. 93-108, jan. 2011.

EVANS, R. G.; STODDART, G.L. Consuming research, producing policy? American Journal of Public Health, v.93, n.3, p.371-79, mar. 2003.

FREIRE, P. Educação como prática da liberdade. $29^{a}$. Ed. Rio de Janeiro: Paz e Terra; 2006.
KIRSCH, I. et al. Adult Literacy in America: a first look at the findings of the national adult literacy survey. Washington, DC: National Center of Education Statistics; 1993.

KOCH, I. G. V. Desvendando os segredos do Texto. São Paulo: Editora Cortez; 2003.

LIMA, S. M. L. Utilização de diretrizes clínicas e resultados na atenção básica à hipertensão arterial. Cadernos de Saúde Pública, v. 25, n. 9, p. 2001-2011, set. 2009.

MARCUSCHI, L.A. Processos de Produção Textual. Análise de Gêneros e Compreensão. Editora Parábola Editorial. 2008.

MÜLLER, M. Comunicação em saúde: binômio assistente e assistido. Psicologia IESB, América do Norte, 1, aug. 2010. Disponível em: http://php.iesb.br/ojs/index.php/ psicologiaiesb/article/view/11/12. Acesso em 01 Ago. 2018. 
NATIONAL WORK GROUP ON LITERACY AND HEALTH.

Communicating with patients who have limited literacy skills: Report of the National Work Group on Literacy and Health. The Journal of Family Practice, v. 46, n. 2, p. 168-76, feb. 1998.

OLIVEIRA, V. Z. ; GOMES, W. B. Comunicação médicopaciente e adesão ao tratamento em adolescentes portadores de doenças orgânicas crônicas. Estudos de Psicologia, v. 9, n. 3, p. 459-469, set./dez. 2004.

PAASCHE-ORLOW M. Caring for Patients with Limited Health Literacy: A 76-Year-Old Man with Multiple Medical Problems. Journal of the American Medical Association, v. 306, n. 10, p. 1122-9, sep. 2011.

PAASCHE-ORLOW, M.K. et al. The prevalence of limited health literacy. Journal of General Internal Medicine, v. 20, n. 2, p. 175-84, feb. 2005.
PACHECO, G.S. et al. Características de Clientes com Doença Renal Crônica: Evidência para o ensino do Autocuidado. Revista de Enfermagem da UERJ, v. 14, n. 3, p. 434-35, jul./set. 2006.

SESSO, R. C. et al. Relatório do censo brasileiro de diálise 2010. Jornal Brasileiro de Nefrologia, v. 33, n. 4, p. 442-447, out./ dez. 2011.

SORENSEN, K. et al. Health literacy and public health: A systematic review and integration of definitions and models. BMC Public Health, v. 12, n. 80, p. 12-80, jan. 2002.

TORRES, H. C. Avaliação estratégia de educação em grupo e individual no programa educativo em diabetes. Revista de Saúde Pública, v. 43, n. 2, p. 291-8, feb. 2009.

WRIGHT, J. A. et al. Development and Results of a Kidney Disease Knowledge Survey Given to Patients With CKD. American Journal of Kidney Diseases, v. 57, n. 3, p. 387-95, mar. 2011. 